\title{
Aproximações entre o legado freireano e a Educação Profissional e Tecnológica: uma análise textual discursiva do Estatuto do Instituto Federal Fluminense
}

Approaches between Freire's legacy and Professional and Technological Education: a textual discursive analysis of the Statute of the Federal Fluminense Institute Aproximaciones entre el legado de Freire y la Educación Profesional y Tecnológica: un análisis textual discursivo del Estatuto del Instituto Federal Fluminense

\author{
ARTHUR DA REZENDE DA SILVA \\ https://orcid.org/0000-0002-4543-7842 \\ Universidade Católica de Petrópolis \\ Programa de Pós-graduação em Educação \\ Petrópolis, RJ, Brasil \\ RAFAEL BASTOS COSTA DE OLIVEIRA \\ https://orcid.org/0000-0003-3694-0435 \\ Universidade Católica de Petrópolis \\ Programa de Pós-Graduação em Educação \\ Petrópolis, RJ, Brasil
}

\begin{abstract}
Resumo: Este artigo objetiva investigar a relação entre o legado freireano e a Educação Profissional e Tecnológica (EPT), com base nesta questão: Em quais aspectos observa-se a influência de Paulo Freire no Instituto Federal Fluminense? Metodologicamente, optou-se pela técnica de análise de dados conceituada como Análise Textual Discursiva (ATD), a partir do documento institucional que reformula o Estatuto do IFF. A análise aponta a presença do legado freireano no Estatuto do IFF, por visar à formação emancipatória do estudante e oportunizar experiências de uma gestão democrática.
\end{abstract}

Palavras-chave: Paulo Freire; Instituto Federal Fluminense; Estatuto; Análise Textual Discursiva.

\begin{abstract}
This article aims to investigate the relationship between Freire's legacy and Professional and Technological Education (EPT), based on this question: In what aspects is Paulo Freire's influence observed at the Federal Fluminense Institute? Methodologically, we opted for the data analysis technique conceptualized as Discursive Textual Analysis (ATD), based on the institutional document that reformulates the IFF Statute. The analysis points to the presence of Freire's legacy in the IFF Statute, as it aims at the emancipatory formation of the student and provides opportunities for democratic management.
\end{abstract}

Keywords: Paulo Freire; Instituto Federal Fluminense; Discursive Textual Analysis. Statute. 
Resumen: Este articulo tiene como objetivo investigar la relación entre el legado de Freire y la Educación Profesional y Tecnológica (EPT), a partir de esta pregunta: ¿En qué aspectos se observa la influencia de Paulo Freire en el Instituto Federal Fluminense? Metodológicamente, optamos por la técnica de análisis de datos conceptualizada como Análisis Textual Discursivo (ATD), a partir del documento institucional que reformula el Estatuto de la IFF. El análisis apunta a la presencia del legado de Freire en el Estatuto de la IFF, ya que apunta a la formación emancipadora del estudiante y brinda oportunidades para la gestión democrática.

Palabras clave: Paulo Freire; Instituto Federal Fluminense; Estatuto; Análisis textual discursivo.

\section{INTRODUÇÃO}

A Educação Profissional e Tecnológica (EPT), com a promulgação da lei 11.892 de 29 de dezembro de 2018, que instituiu os Institutos Federais de Educação, Ciência e Tecnologia (Institutos Federais), alcança novas possibilidades de pesquisa e reflexão, afinal, a EPT, na argumentação de Arroyo (2019), provoca interrogações desafiantes, até desestruturantes para o pensamento pedagógico sobre o direito à educação de trabalhadores: "Que novas interrogações, que novos saberes aprender com a EPT?” (ARROYO, 2019, pág.5).

$\mathrm{Na}$ tentativa de explorar uma dessas muitas interrogações, este artigo tem como finalidade voltar-se para a investigação da relação entre Paulo Freire e a EPT, nada mais oportuno neste ano de 2021, em que o referido teórico completaria 100 anos de vida. É válido ressaltar que Paulo Freire é conhecido, mundialmente, pelo caráter transformador de sua teoria pedagógica, cujo foco foi a incessante busca por uma sociedade mais igualitária, através de uma proposta/ experiência educacional emancipatória e humanizadora.

Num momento em que o pânico toma conta da sociedade, em que nossas vidas estão de forma provisória e em suspenso (FRIGOTTO, 2009), resultante da "universalidade perversa" (LATOUR, 2020), cujas características são migrações bem mais abrangentes, incluindo também os agentes não humanos como vírus, bactérias, gases atmosféricos etc. (COSTA, 2020), inspirarmo-nos, em Paulo Freire, possibilita-nos alento, esperança, num momento em que "A nova universalidade consiste em sentir que o solo está em vias de ceder." (LATOUR, 2020, pág.18).

Com o intuito de dar consistência à referida investigação, este estudo se baseou na seguinte questão-problema: Em quais aspectos é possível observar a influência de Paulo Freire no Instituto Federal Fluminense (IFF)? 
As investigações já realizadas ajudam verificar que há essa sintonia entre o legado freireano com as bases dos Institutos Federais. Esta constatação será devidamente explorada no decorrer do texto.

Para responder a esta questão, optou-se pela pesquisa qualitativa, de cunho bibliográfico e documental, por meio de um levantamento das obras de Paulo Freire e de documentos oficiais, em especial a Resolução no 40, de 22 de dezembro de 2017, do IFF, que aprova a reformulação do Estatuto da referida instituição. Para tratar esse corpus foi utilizada a análise textual discursiva (ATD), que "assume pressupostos que a localizam entre os extremos da Análise de Conteúdo e Análise de Discurso (MORAES, GALIAZZI, 2016, pág.162). Sendo assim, munidos deste aporte metodológico, o objetivo desta pesquisa é verificar as aproximações do legado freireano e das tendências pedagógicas de que fez parte, na reformulação do Estatuto do IFF.

Para alcançar o objetivo elencado, o referido artigo, além desta introdução e do percurso metodológico, apresenta, uma breve exposição sobre os Institutos Federais e seus deslocamentos em relação à histórica dualidade da EPT (entre o trabalho manual e o trabalho intelectual), em seguida, é realizada uma ATD do novo Estatuto do IFF e sua relação com as concepções freireanas, e por fim, as considerações sobre essa possível sintonia entre Paulo Freire e as bases conceituais e legais do IFF.

\section{PERCURSO METODOLÓGICO}

O caminho metodológico deste artigo é a pesquisa documental, tendo como corpus o Estatuto do IFF. A utilização deste método oportuniza ao pesquisador sistematizar uma gama de informações sobre leis e documentos, dando sustentação para a descrição e inferência do fenômeno sobre o qual se debruça. (TRIVIÑOS, 2008). Corroborando o destacado anteriormente, há os ensinamentos de Lüdke e André (2020), que definem a análise documental como uma técnica valiosa, visto que pode complementar informações obtidas por outras técnicas, ou por proporcionar novos aspectos de um tema ou problema.

As autoras ainda elucidam que os documentos são uma fonte estável e rica, visto que persistem ao longo do tempo, podendo ser de base para novos estudos, gerando mais estabilidade aos resultados alcançados. As autoras alertam também que, enquanto uma técnica exploratória, há limitações, pois, a análise documental aponta problemas que devem ser mais bem descritos por meio de outros métodos. Certos de que este trabalho não esgota as diversas interrogações do campo da EPT, espera-se que o artigo inspire pesquisadores a explorarem a temática. 
Como técnica de interpretação de dados, utilizamos a ATD, que compreende uma metodologia de inferências de informações de natureza qualitativa com o objetivo de produzir novas compreensões acerca de fenômenos e discurso, tendo como característica um movimento interpretativo de caráter hermenêutico (MORAES,GALIAZZI, 2016).

A ATD encontra na pesquisa em educação um espaço amplo para a criticidade e investigação, como podemos observar nas pesquisas de Mesquita (2020), que estuda os percursos formativos dos projetos pedagógicos das licenciaturas em química, a de Ferreria, Silva, e Carreiro (2020), que investiga o ensino de filosofia, e Guidotti e Heckler, cujo campo de investigação é a formação de professores de ciências e a de Antiqueira e Machado (2020), que utiliza a ATD na pesquisa de professores de matemática. Assim, observa-se a fonte de experimentações advindas da ATD e a qual nos instigou enquanto importante técnica de análise de dados.

Portanto, nota-se que as pesquisas qualitativas vêm utilizando, com frequência, as análises textuais, como a ATD, seja por meio de textos existentes, seja por meio de entrevistas ou observações. A análise do corpus, por meio da ATD, engloba os seguintes elementos: desmontagem do texto, em que o texto é examinado nos detalhes, produzindo unidades constituintes; estabelecimento de relações, que é a construção de sintonias entre as unidades de sentido, por meio da categorização e por fim, a captação do novo emergente, sendo o resultado da interpretação a partir de produção de um metatexto (MORAES, GALIAZZI, 2016). O detalhamento dessas informações está consolidado na seção "Aproximações entre Paulo Freire e IFF: uma análise textual discursiva" deste artigo.

\section{INSTITUTOS FEDERAIS DE EDUCAÇÃO, CIÊNCIA E TECNOLOGIA: DESLOCAMENTOS DAS ROTAS PARADIGMÁTICAS DA EPT}

A EPT no Brasil é um campo repleto de desafios, em virtude das incompreensões e/ou reducionismos associados a esta modalidade de ensino. Um dos reducionismos em relação à EPT é o fato de limitá-la aos pobres, constituindose, assim, apenas, como mão de obra alienante, atendendo, portanto, ao mercado de trabalho capitalista e desigual. Enfim, o que simboliza, historicamente, a EPT no Brasil é o dualismo: a velha e sempre revisitada distinção entre "quem sabe pensar" e "quem sabe fazer", entre o manual e o intelectual. Esse dualismo foi ratificado pelo Decreto 2.208 de 17 de abril de 1997 que em seu artigo 5 não 
permitia a articulação entre EPT e a formação básica, confirmando que a referida modalidade só poderia ser ofertada na forma concomitante e/ou subsequente ao ensino médio (BRASIL, 1997).

Por meio da luta dos que acreditam no trabalho como princípio educativo e na formação do trabalhador enquanto um sujeito em sua totalidade, tendo direito a toda uma estrutura de conhecimentos diversos, em 23 de julho de 2004 foi publicado o Decreto $n^{\circ} 5.154$, que retomou a possibilidade de articulação entre o ensino médio com o currículo da EPT, "sendo o curso planejado de modo a conduzir o aluno à habilitação profissional técnica de nível médio, na mesma instituição de ensino, efetuando-se matrícula única para cada aluno (BRASIL, 2008)".

Essa retomada da articulação potencializa a formação da classe trabalhadora ao mesmo tempo que carrega muitos desafios àqueles que almejam uma escola que autorize os trabalhadores ao acesso às aprendizagens, possibilitando a compreensão da realidade e sua intervenção nela (RAMOS, 2007). É uma proposta ousada cujo objetivo é a integração curricular pela ciência, cultura, trabalho e tecnologia. E dentro dessa ousadia, em 29 de dezembro de 2008, são constituídos os Institutos Federais, que completaram em 2020, 12 anos, alcançando a marca de mais de um milhão de estudantes ${ }^{1}$.

É oportuno ratificar que a expansão dos Institutos Federais alcançou territórios antes não assistidos por iniciativas de formação humana e profissional. Em 2020, a referida rede passou a contar com 665 unidades distribuídas entre as 27 unidades federadas do país, tornando-se uma das políticas de maior capilaridade no interior do Brasil. Essa capilaridade pode ser comprovada pelo Relatório de Tribunal de Contas da União (TCU), de 2013, que constatou que mais de $80 \%$ da expansão dos Institutos Federais ocorreu nas cidades do interior do Brasil, muitas delas com menos de 20 mil habitantes, o que representaria, para a referida população, a única possibilidade de acesso da população a uma instituição federal de ensino, mantida pela União (TRIBUNAL DE CONTAS DA UNIÃO, 2013). A expansão da rede federal de educação profissional e tecnológica (REPCT) representa um marco na história da EPT, como vemos na fala de Pacheco:

$1 \quad$ A Rede federal completa 12 anos e ultrapassa mais de um milhão de matrículas. Ministério da Educação (ME) Disponívelem:<https://www.gov.br/mec/pt-br/assuntos/noticias/rede-federal-completa-12anos-e-ultrapassa-mais-de-um-milhao-de-matriculas $>$ Acesso em: 06.jan.2021. 
A Rede Federal, por sua excelência e vínculos com a sociedade produtiva, tem condições de protagonizar um Projeto Político-Pedagógico inovador, progressista e capaz de construir novos sujeitos históricos, capazes de se inserir no mundo do trabalho, compreendendo-o e transformando-o na direção de um novo mundo possível, capaz de superar a barbárie neoliberal e restabelecer o ideal da modernidade de liberdade, igualdade e fraternidade, sob a ótica das novas possibilidades abertas à humanidade neste princípio de século. Os Institutos Federais de Educação Ciência e Tecnologia são a síntese daquilo que de melhor a Rede Federal construiu ao longo de sua história e das políticas de educação profissional e tecnológica do governo federal. São caracterizados pela ousadia e inovação, necessárias a uma política e um conceito que buscam antecipar aqui e agora as bases de uma escola contemporânea do futuro e comprometida com uma sociedade radicalmente democrática e socialmente justa. (PACHECO, 2010, pág.11)

Assim, essa abrangência dos Institutos Federais, principalmente, no interior do país, possibilita o diálogo intenso e vivo com a realidade local e regional, atuando na busca de soluções para a exclusão social, tão característica de nossa nação. Logo, cada Instituto Federal deve ter sintonia com a região em que está inserido, comprometendo-se com o desenvolvimento local e regional, num monitoramento efetivo do perfil socioeconômico-político-cultural da região de que fazem parte (BRASIL, 2010).

Os Institutos Federais se deslocam das rotas que foram impostas, historicamente, à EPT, visto que em seu bojo de finalidades está a busca pela qualidade social orientada pela formação integral de cidadãos-trabalhadores emancipados, em detrimento, conforme esclarece Moura (2007), a uma lógica assistencialista da EPT coesa com uma sociedade escravocrata totalmente dependente da coroa portuguesa. Em consonância a esta argumentação, temse Freire (1967) que destaca uma explicação sobre o momento histórico que favoreceu o desenvolvimento desse modelo de EPT, a que os Institutos Federais se opõem:

Em verdade, o que caracterizou, desde o início, a nossa formação, foi, sem dúvida, o poder exacerbado. Foi a robustez do poder em torno de que foi se criando um quase gosto masoquista de ficar sobre ele a que correspondia outro, o de ser o todo-poderoso. Poder exacerbado a que foi associando sempre submissão. Submissão de que decorria, em consequência, ajustamento, acomodação e não integração. Esta foi, na verdade, a constante de toda a nossa vida colonial. Sempre o homem esmagado pelo poder. Poder dos senhores das terras. Poder dos governadores-gerais, dos capitães gerais, dos vice-reis, do capitão-mor. Nunca, ou quase nunca, interferindo o homem na constituição e na organização da vida comum (FREIRE, 1967, p. 74) 
Para o entendimento da análise do Estatuto do $\mathrm{IFF}^{2}$, na próxima seção, é válido contextualizarmos algumas informações sobre a referida instituição, dentre elas que possui 11 campi nas diversas regiões do Estado do Rio de Janeiro, como Norte, Noroeste, Lagos, Centro Norte e Metropolitana, tendo sua Reitoria na cidade de Campos dos Goytacazes. Optamos por fazer uma tabela com informações retiradas da Plataforma Nilo Peçanha ${ }^{3}$, criada em 2018, cujo objetivo é ser um ambiente virtual com todas as estatísticas da RFEPCT. Tais informações subsidiam os indicadores de gestão fiscalizados pela Secretaria de Educação Profissional e Tecnológica (SETEC), do Ministério da Educação (MEC).

\section{Quadro 1 - Informações do IFF a partir da Plataforma Nilo Peçanha, ano Base de 2019.}

\begin{tabular}{|c|c|}
\hline Cursos & 198 \\
\hline Matrículas & 21.144 \\
\hline Ingressantes & 7.301 \\
\hline Concluintes & 3.574 \\
\hline Vagas & 8.685 \\
\hline Inscritos & 39.423 \\
\hline
\end{tabular}

Fonte: Elaborado pelos autores a partir de Brasil (2020)

Pelos dados retratados, observa-se a pujança da instituição, a partir do quantitativo de cursos e estudantes matriculados. Ressaltamos que tal instituição tem sua sede no interior do Estado do Rio de Janeiro, o que reforça, sobremaneira, sua importância para a classe trabalhadora dessa região, em geral, esquecidas das políticas públicas de grande porte. O IFF tem cursos técnicos integrados ao ensino médio, cursos técnicos concomitantes e/ou subsequentes ao ensino médio, cursos na modalidade de Educação de Jovens e Adultos, cursos de graduação, e também mestrado e doutorado profissionais. A seguir, partimos para a ATD do documento oficial da instituição que versa sobre seus princípios, seus objetivos, sua estrutura, enfim, seu Estatuto. E procuraremos responder em que medida as ideias de Freire estão elencadas nesse documento.

2 Conheça o IFF. Disponível em:http://portal1.iff.edu.br/conheca-o-iffluminense/conheca-oiffluminense. Acesso em: 06.jan.2021.

3 Acesse a Plataforma Nilo Peçanha. Disponível em: http://portal.mec.gov.br/component/tags/tag/ plataforma-nilo-pecanha. Acesso em 20.jan.2021. 


\title{
APROXIMAÇÕES ENTRE PAULO FREIRE E IFF: UMA ANÁLISE TEXTUAL DISCURSIVA
}

Com a impregnação do material em análise, que ressaltamos, oriundas do Estatuto do IFF, permitiu o surgimento das categorias e unidades de sentido elencadas no quadro a seguir. Como nos ensinam Moraes e Galiazzi (2016), a fragmentação não esgota as análises pretendidas, havendo a limitação própria de um artigo científico e, por isso, optamos por partir para as categorias finais e suas respectivas unidades de sentido, com base nos conhecimentos prévios, a partir dos objetivos específicos do artigo e da análise do corpus, que gerou os dados a serem impregnados. Ainda sobre a ATD, é válido destacar o seguinte apontamento:

\begin{abstract}
Realizar uma ATD é pôr-se no movimento das verdades, dos pensamentos. Sendo processo fundado na liberdade e na criatividade, não possibilita que exista nada fixo e previamente definido. Exige desfazer-se de âncoras seguras para se libertar e navegar em paragens nunca antes navegadas. É criar os caminhos e as rotas enquanto se prossegue, com toda a insegurança e incerteza que isso acarreta. Ainda que o caminho finalmente resultante seja linear, por força da linguagem em que precisa ser expresso, em cada ponto há sempre infinitas possibilidades de percursos. Daí mais uma razão de segurança e angústia. Envolver-se com a ATD requer do pesquisador assumir uma viagem sem mapa, aceitar o desafio de acompanhar o movimento de um pensamento livre e criativo, de romper com os caminhos já pontos para construir os próprios... (MORAES, GALIAZZI, 2016, p. 188)
\end{abstract}

Dessa forma, a partir das leituras geridas pela ATD, organizamos as unidades de significados, os títulos e as categorias iniciais e categorias finais/ emergentes. Assim, imbuídos pelo desejo de construirmos o metatexto, característico da ATD, segue a síntese de nossa impregnação dos dados desta pesquisa, a partir da análise do Estatuto do IFF e dos ideais de Paulo Freire. Antes, destacamos também a seguinte declaração de Moraes e Galiazzi (2016):

Pesquisas que valorizem o discursivo vão do dito ao não dito, num movimento permanente entre o manifesto e oculto, num afastamento dos sentidos imediatos para a identificação de sentidos contextualizados, cuja explicitação requer inferências cada vez mais aprofundadas. Este esforço de captar mensagens conscientes e inconscientes implica um movimento de ultrapassagem de uma leitura de primeiro plano para outra de maior profundidade. (MORAES, GALIAZZI, 2016, pág. 83) 


\section{Quadro 2 - Categorias e Unidades de Sentido do Estatuto do IFF e a relação com Paulo Freire}

\begin{tabular}{|c|c|}
\hline Categorias finais/emergentes & Unidades de sentido \\
\hline \multirow{5}{*}{ 1- Formação libertadora e humanizada dos estudantes } & Compromisso com a Justiça Social \\
\hline & Extensão, Pesquisa e Sociedade \\
\hline & Compromisso com a educação inclusiva e emancipatória \\
\hline & Processo investigativo e educativo às demandas sociais \\
\hline & Desenvolvimento socioeconômico e cultural \\
\hline \multirow{5}{*}{$\begin{array}{l}\text { 2- Gestão Democrática e mecanismos de participação } \\
\text { democrática na EPT }\end{array}$} & Conselho Superior \\
\hline & Conselho de Campus \\
\hline & Conselho de Ensino, Pesquisa, Extensão e Inovação \\
\hline & $\begin{array}{c}\text { Comissão Permanente de Pessoal Docente e Interna de } \\
\text { Supervisão do Plano de Carreira dos Técnicos Administrativos } \\
\text { em Educação }\end{array}$ \\
\hline & Comissão Permanente de Assuntos Discentes \\
\hline
\end{tabular}

Fonte: Elaborado pelos autores.

\section{Categoria 1 - Formação libertadora e humanizada dos estudantes}

Uma das convicções de Paulo Freire é, indubitavelmente, uma formação que proporcione emancipação do sujeito. Tal emancipação deve permitir ao homem ser sujeito por inteiro, construindo-se como pessoa que transforme o mundo por meio de uma formação que não subjugue o cidadão ao modelo capitalista vigente (FREIRE, 2006). Ancorado a esse pensamento de Freire, têm-se no Estatuto do IFF princípios norteadores para todos os seus campi, como o seguinte "compromisso com a justiça social, equidade, cidadania, ética, preservação do meio ambiente, transparência e gestão democrática;" (IFF, 2017, pág. 3).

No processo da unitarização da ATD, destacamos a palavra "compromisso", que nos remete a pacto, o que é essencial em uma instituição do porte do IFF, por atender a classe trabalhadora. Esse pacto é amplo, pelo que está descrito no princípio elencado anteriormente, pois engloba questões urgentes para uma formação de cidadãos, que seja apta a tornar o trabalhador "um agente político, para compreender a realidade e ser capaz de ultrapassar os obstáculos que ela apresenta, de pensar e agir na perspectiva de possibilitar as transformações políticas, econômicas, culturais e sociais imprescindíveis para a construção de um outro mundo possível" (BRASIL, 2010, p.33).

Essa formação omnilateral do cidadão-trabalhador encontra coro na argumentação de Freire (2017) quando o teórico elucida que é fundamental que o estudante assuma um papel de protagonista da produção de inteligência do 
mundo e que não seja um recebedor dos conteúdos organizados pela instituição. Nessa esteira, têm-se as finalidades e características do IFF, que direcionam sua comunidade para um diálogo estreito com o território do qual fazem parte, ao instituir a necessidade de "desenvolver a educação profissional e tecnológica como processo educativo e investigativo de geração e adaptação de soluções técnicas e tecnológicas às demandas sociais e peculiaridades regionais;” (IFF, 2017, pág.4).

Nessa perspectiva, observa-se que o IFF preza por uma ação dialógica entre escola e sociedade, rompendo com o paradigma de instituições de ensino enquanto "ilhas isoladas", exigindo, de sua comunidade escolar interna, uma sintonia com os sujeitos das classes populares, colaborando para que saiam da condição de oprimidos, pois somente "através de sua permanente ação transformadora da realidade objetiva é que os homens, simultaneamente, criam a história e se fazem seres histórico-sociais" (FREIRE, 2003, pág. 92). Esse espaço para as classes populares e para uma formação de emancipadora no IFF fica evidenciado no seguinte trecho de seu estatuto ao tratar do currículo:

Art. 34. O currículo no Instituto Federal Fluminense está fundamentado em bases filosóficas, epistemológicas, metodológicas, socioculturais e legais, expressas no seu projeto político institucional, sendo norteado pelos princípios da estética, da sensibilidade, da política da igualdade, da ética, da identidade, da interdisciplinaridade, da contextualização, da flexibilidade e da educação como processo de formação na vida e para a vida, a partir de uma concepção de sociedade, trabalho, cultura, educação, tecnologia e ser humano. (IFF, 2017, pág.18)

A unidade de sentido "compromisso com a educação inclusiva e emancipatória" vai ao encontro desse currículo comprometido com a formação integral, afinal, "Nós fazemos o currículo e o currículo nos faz" (SILVA, 1995, p. 194). Palavra muito difundida nos espaços escolares, e, por este motivo, mal compreendida por muitos sujeitos. É necessário e urgente desconstruirmos a ideia de currículo como apenas "grade" disciplinar ou matriz disciplinar. Currículos são práticas pedagógicas que contribuem para a construção de identidades dos alunos, em outras palavras, currículos são todos os esforços desenvolvidos na escola com intenções educativas (MOREIRA, CANDAU, 2007).

É muito alvissareiro o que o Estatuto do IFF apresenta como concepção de currículo e tal conceito é harmônico à tese defendida por Freire ao enfatizar que a transformação democrática da sociedade se estabelece quando a escola não coloca em oposição o ensino dos conteúdos e a realidade. É fundamental que a educação entusiasme a presença das classes sociais populares na luta pela superação das injustiças sociais (FREIRE, 2001). Essa máxima está em congruência com o Estatuto do IFF quando apresenta como finalizada que sua oferta de cursos seja 
afinada com a consolidação e fortalecimento "dos arranjos produtivos, sociais e culturais locais, identificados com base no mapeamento das potencialidades de desenvolvimento socioeconômico e cultural no âmbito de atuação do Instituto Federal Fluminense.” (IFF, 2017, pág.4).

Nesse prisma, fica especificado o esforço da instituição em consolidar seu estatuto como um documento de resistência à histórica dualidade que marca a EPT no Brasil, que tem em seu bojo "o ser humano dividido historicamente pela divisão social do trabalho entre a ação de executar e a ação de pensar, dirigir ou planejar.” (RAMOS, 2014, pág.84). A congruência com as concepções de Paulo Freire ficam evidenciadas no Estatuto do IFF, visto que seus princípios, objetivos e currículo apontam para uma escola que "respeita os educandos, não importa qual seja sua posição de classe e, por isso mesmo, leva em consideração, seriamente, o seu saber de experiência feito, a partir do qual trabalha o conhecimento com rigor de aproximação aos objetos.” (FREIRE, 2001, pág. 50).

Por fim, cabe destacar que Freire pertenceu à tendência progressista libertadora, cuja finalidade é uma educação voltada para autonomia, criticidade e transformação da sociedade, em que os conteúdos devem partir do ambiente no qual os estudantes vivem (LIBÂNEO, 2003). Essa contextualização dos conteúdos fica exemplificada no Projeto Político-Pedagógico Institucional 20182022 da instituição (IFF, 2018), quando pontua a decisão do IFF para a efetivação da pesquisa como um princípio pedagógico, enumerando a emancipação humana enquanto objetivo:

Tratar da pesquisa numa ótica pedagógica é compreendê-la como agente possibilitador de emancipação humana, que deve propiciar ao estudante a produção de novos conhecimentos, a compreensão da sua realidade e a construção e o fortalecimento de sua autonomia. O fomento à pesquisa como uma prática diária entre discentes e docentes é uma atividade reflexiva e investigativa que proporciona o conhecimento teórico e empírico acerca das temáticas a serem investigadas, repercutindo no processo educativo e formativo do sujeito. (IFF, 2018, Pág.12-13)

E para exemplificar essa perspectiva de emancipação, pode-se citar o edital 140 do IFF, de 23 de dezembro de 2020, que regulamenta processo de seleção de projetos de cultura e diversidade, englobando as seguintes frentes integradoras: Núcleo de Estudos Afro-brasileiros e indígenas (NEABI), Núcleo de Estudos sobre Gênero, Diversidade e Sexualidades (NUGEDIS), Centro de Memória e Projeto Cultural': 
Art. $4^{\circ}$ As propostas devem demonstrar de maneira objetiva as articulações entre as ações propostas nos projetos e a dimensão de ensino, de extensão ou de ensino e extensão nos seguintes itens:

I - impacto na formação do estudante;

II - interação dialógica em relação aos agentes parceiros do projeto e ao público;

III - impacto e transformação em relação aos agentes parceiros ou ao público;

IV - interdisciplinaridade entre áreas de conhecimento, cursos ou campi;

$\mathrm{V}$ - aderência a pelo menos um dos 17 (dezessete) Objetivos de Desenvolvimento Sustentável (ODS/ONU - Agenda 2030);

VI - indissociabilidade entre Ensino, Pesquisa e Extensão. (IFF, 2020, pág.1-2, grifos nossos)

Assim, por meio de programas institucionalizados, o IFF promove a oportunidade de potencializar a aprendizagem dos estudantes com ações extensionistas e integradoras. Nesse sentido, no processo desafiador da procura de redes coletivas de significados construídos, em que o pesquisador se desafia a depreender e pormenorizar o corpus proposto (MORAES, GALIAZZI, 2016), o referido edital se enquadra na unidade de sentido "Extensão" e "Pesquisa", em que observamos o sincronismo com as ideias freirianas quando elencam a pesquisa enquanto um princípio pedagógico:

Art. 37. As ações de extensão constituem um processo educativo, cultural e científico que articula o ensino e a pesquisa de forma indissociável, para viabilizar uma relação transformadora entre o Instituto Federal Fluminense e a sociedade. Art. 39. As ações de pesquisa constituem um processo educativo para a investigação e o empreendedorismo, visando à produção de conhecimento, à inovação e à solução de problemas científicos e tecnológicos, envolvendo todos os níveis e modalidades de ensino, com vistas ao desenvolvimento social.

Art. 40. As atividades de pesquisa têm como objetivo formar recursos humanos para a investigação, produção de conhecimento, empreendedorismo e difusão de conhecimentos culturais, artísticos, científicos e tecnológicos, sendo desenvolvidas em articulação com o ensino e a extensão, ao longo de toda a formação profissional, consignando em seu orçamento recursos para esse fim. (IFF, 2017, pág.4).

Por fim, essa interseção entre pesquisa e extensão, como ações pedagógicas, vão ao encontro do que Freire menciona sobre estarmos abertos ao diálogo, visto que o que nos move, como cidadãos-reflexivos, é o constante aprendizado. Nossa segurança repousa na consciência de que somos inconclusos, e se essa inconclusão pode representar ignorância, por outro, abre-nos o caminho para conhecer novos fluxos de vida (FREIRE, 2017). E a consciência dessa 
inconclusão por parte do estudante se constitui como uma resistência ao modelo de escola como um aparelho das classes dominantes, possibilitando o surgimento de uma "contraescola":

\begin{abstract}
Portanto, a contraescola emerge da resistência à escola do mundo ao avesso, apresentando-se como uma alternativa a esse modelo hegemônico de cultura escolar. Em outras palavras: podemos compreender a contraescola como sendo as formas contra-hegemônicas de se pensar a educação, desde seu caráter sistêmico e estrutural até as experiências pedagógicas específicas que buscam resistir aos modelos educacionais dominantes. (BENVINDO, 2020, pág.18)
\end{abstract}

Entretanto, os trechos anteriormente citados (do documento do IFF) apresentam elementos também conflitantes com a perspectiva freiriana, pois contemplam a categoria empreendedorismo, junto com o princípio educativo da indissociabilidade entre ensino, pesquisa e extensão.

Entendemos que o legado dialético freiriano, auxilia na própria percepção destas contradições dos marcos institucionais aqui investigados, pois o IFF tem como vocação o debate da educação profissional, esta podendo ser pensada, analiticamente, pela inserção profissional acrática ou contendo, por exemplo, o trabalho como princípio educativo (GRAMSCI, 1978).

\title{
CATEGORIA 2 - GESTÃO DEMOCRÁTICA E MECANISMOS DE PARTICIPAÇÃO DEMOCRÁTICA NA EPT
}

Democracia no Brasil é altamente relacionada à eleição, a voto direto. Porém, democracia não se limita a "voto", sendo um processo de construção. Mas é aí o grande desafio: como fazê-la se tornar um processo? Como avançar para além de uma democracia de conveniência retórica? São inquietações que se manifestam, em grande medida, na escola pública. O que é gestão democrática na escola? Como consolidar? Não responderemos estas questões neste texto, em virtude de nossas limitações, mas julgamos pertinente trazer essas ponderações para subsidiar a problematização da relação de Freire e o Estatuto do IFF, corpus de análise deste artigo.

Nosso país tem como marca ter surgido dentro de condições negativas às experiências democráticas, visto que ocorreu uma colonização predatória, que, indubitavelmente, não gerou possibilidades do desenvolvimento de uma mentalidade flexível no homem brasileiro, condição essencial para um clima cultural democrático (FREIRE, 1967). Essa falta de experiência dialógica que marca a história brasileira se relaciona com a justificativa de Latour (2020) sobre os colonizados se defenderem do caráter predatório da dominação: 
Mas de onde vem tanto pânico? do mesmo profundo sentimento de injustiça experimentado por aqueles que viram privados de suas terras à época das conquistas, depois durante a colonização e, por fim, durante a era do 'desenvolvimento': uma força vinda de fora o despoja de seu território e você não pode detê-la. Se é isto a globalização, então, compreendemos retrospectivamente por que resistir sempre foi a única solução por que os colonizados sempre tiveram razão em se defender. (LATOUR, 2020, pág. 18)

Assim, o papel da escola, principalmente a pública, e a luta por sua gestão democrática, encontra coro na sociedade brasileira que precisa de um local para iniciar suas experiências de participação, fazendo este país encontrar-se consigo mesmo (FREIRE, 1967). E ao proceder a ATD do corpus deste artigo, observa-se um alinhamento a esta luta pela gestão democrática e instrumentos para consolidálo. No Estatuto do IFF, fica evidenciado o caráter de uma gestão compartilhada, visto o número significativo de conselhos paritários como o "conselho superior", "conselho de campus", "comissão permanente de assuntos discentes (CPAD)", dentre outras unidades de sentido analisadas, como se observa no exemplo a seguir: "Art. 31. A CPAD é comissão multicampi de representação estudantil, instituída na forma definida no Regimento Geral do IFFluminense, com objetivo de debater, elaborar e propor questões do interesse dos estudantes." (IFF, 2017, pág. 17)

Estar instituída uma comissão cujo foco seja o estudante e suas demandas é um exemplo de como pode se configurar uma gestão democrática, desde que haja um envolvimento da comunidade escolar na tomada de decisões, favorecendo uma compreensão, por parte dela, dos objetivos, metas, estruturação, enfim, de todas as relações da escola (LIBÂNEO, 2008). E se esta tomada de decisão parte dos estudantes, é um alento para a falta de experiência democrática, como citado anteriormente, e representa a oportunidade de ser "um processo em que os estudantes e professores fazem perguntas críticas acerca do mundo em que vivem, sobre as realidades materiais que ambos experimentam cotidianamente e em que refletem sobre quais ações eles podem realizar para mudar essas condições materiais" (AU, 2011, pág. 251).

Prosseguindo com a ATD e sua impregnação, destacamos o Conselho Superior do IFF, órgão máximo e de caráter deliberativo e consultivo, cuja composição é bem diversificada, com representantes dos docentes, dos discentes, dos técnicos administrativos, dos egressos, sociedade civil, como entidades patronais e convidados por edital público, e até representação do Ministério da Educação (IFF, 2017). Democracia demanda participação e disposição ao diálogo, por isso, o ambiente democrático é de difícil consolidação. O exemplo do IFF pode representar uma oportunidade de se efetivar o que preceitua a Constituição Federal da República, quando preceitua, em seu artigo 206, os 
princípios da organização da educação nacional "Gestão democrática do ensino público na forma da lei”. Fica claro no Estatuto do IFF esse princípio a partir das competências do Conselho Superior:

Art. 9. ${ }^{\circ}$ Compete ao Conselho Superior:

I. aprovar as diretrizes para atuação do Instituto Federal Fluminense e zelar pela execução de sua política educacional;

II. aprovar as normas e coordenar o processo de consulta à comunidade escolar para escolha do Reitor do Instituto Federal Fluminense e dos Diretores-Gerais dos campi, em consonância com o estabelecido nos arts. 12 e 13 da Lei n. ${ }^{\circ}$ 11.892/2008;

III. apreciar e aprovar o plano de desenvolvimento institucional do Instituto Federal Fluminense;

IV. apreciar, aprovar e acompanhar a execução do plano de ação e da proposta orçamentária anual do Instituto Federal Fluminense;

V. aprovar proposta de criação, encerramento ou manutenção de cursos, avaliando critérios de demanda, permanência e êxito, em conformidade com o PDI;

VI. aprovar a organização didática e pedagógica, os regulamentos internos e as normas disciplinares;

VII. aprovar os regimentos internos dos colegiados / conselhos do IFFluminense; (IFF, 2017, pág. 9)

Pelas competências elencadas no Estatuto, o Conselho Superior e seus conselheiros têm uma árdua e importante atuação nos assuntos de repercussão geral na instituição, como a aprovação e fiscalização do orçamento, aprovação da organização didática e pedagógica, permanência e êxito estudantis e eleições diretas e paritárias para diretores-gerais dos campi e do cargo de Reitor. Com espaços múltiplos como o Conselho Superior, Conselhos de campi e Conselho de Ensino, Pesquisa e Extensão, o IFF se coloca como uma instituição que cultiva o espaço democrático, como demonstra Souza (2019), ao apontar como condições de gestão democrática o provimento de cargos de diretores por critérios técnicos combinados com escolha da comunidade, a existência e o pleno funcionamento dos conselhos escolares e a efetivação do projeto político pedagógico (PPP).

Mas o mesmo autor pondera que o ambiente democrático só ocorre, de fato, se os sujeitos da comunidade escolar estiverem dispostos ao diálogo (SOUZA, 2019). Em congruência com as argumentações anteriores, tem-se Freire (2017) quando explana que para a estruturação da democracia e participação política na escola é fundamental à autonomia, em que os sujeitos se assumam como seres sociais e históricos, como seres pensantes, como realizadores de sonhos. No processo de unitarização, escolhemos as comissões dos trabalhadores da educação, professores e técnicos-administrativos em educação como elemento condicionante da categoria em tela: 
Art. 29. A CPPD é Comissão instituída por previsão expressa da Lei 12.772, de 28 de dezembro de 2012, com objetivo definido no seu $\int 1^{\circ}$ do Art. 26, de prestar assessoramento ao colegiado competente ou dirigente máximo da Instituição de ensino, para formulação e acompanhamento da execução da política de pessoal docente, com forma de constituição, competência e limites de atuação definidos no Regimento geral e no seu regimento específico.

Art. 30. A CIS-PCCTAE é Comissão instituída com base na Portaria do MEC $\mathrm{n}^{\circ} 2.519$, de 15 de julho de 2005, que define conjunto de ações relacionadas aos interesses dos Servidores Técnico- Administrativos em Educação, especialmente no que tange ao acompanhamento do plano de carreira, evolução e enquadramentos, assim como o acompanhamento de identificação dos ambientes organizacionais proposto pela área de pessoal entre outras atribuições presentes no Regimento geral e no seu regimento específico. (IFF, 2017, pág. 17)

Essas comissões formalizadas no documento máximo da instituição reforçam a importância dos trabalhadores da educação na formulação das políticas institucionais, e, infelizmente, a participação dos agentes da educação, por incrível que possa parecer, é mínima nos processos decisórios das escolas públicas em geral. Essas comissões possuem um simbolismo importante para a concretização de um princípio da democratização, visto que promovem na comunidade escolar o equilíbrio das responsabilidades: "Participação competente é o caminho para a construção da autonomia. Mediante a prática dessa participação, é possível superar o exercício do poder individual empregado nas escolas e promover a construção do poder da competência, centrado na unidade social escolar como um todo." (LÜCK, 2008, p. 41).

\section{CONSIDERAÇÕES FINAIS}

O centenário de Paulo Freire representa a possibilidade de fazer emergir na população atitudes, resistências, potências frente aos avanços dos retrocessos que caracterizam o Brasil atualmente, como as contrarreformas educacionais no Ensino Médio (MOTTA e FRIGOTTO, 2017), a crescente onda do populismo da Direita e dos partidos e movimentos da extrema direita (AFONSO, 2020) e o Novo Regime Climático (LATOUR, 2020).

Este artigo problematiza a relação do legado freireano com princípios e fundamentos elencados no Estatuto do IFF, procurando responder à questão: Em quais aspectos é possível observar a influência de Paulo Freire nos Institutos Federais?

Como caminho metodológico para a questão pontuada, utilizou-se a pesquisa qualitativa, por meio do estudo de caso, a partir do novo modelo de EPT, caracterizado neste artigo pelo IFF; como instrumento de coletas de dados, um documento oficial do IFF, no caso, o Estatuto recentemente atualizado, e por 
fim, enquanto técnica de análise dos dados, optou-se pela ATD, que possibilita ao pesquisador uma impregnação intensa com os materiais analisados, gerando, no decorrer do processo, uma intensa aprendizagem, ao mesmo tempo que colabora a encaminhar a comunicação dessas mesmas aprendizagens e das novas compreensões conquistadas (MORAES, GALIAZZI, 2016).

Nesse movimentar-se necessário com a ATD, foi possível constatar a confirmação da hipótese, uma vez que é notória a presença da concepção de Freire na gênese do IFF. As categorias finais e emergentes, numa tentativa de contribuir com a compreensão dos fenômenos investigados, como nos ensinam Moraes e Galiazzi (2016), não são taxativas, pois o exercício de categorização não é inteiramente objetivo, já que oportuniza subjetividades, inquietações, enfim, é a hermenêutica: 1- Formação libertadora e humanizada dos estudantes e 2- Gestão democrática e mecanismos de participação democrática no IFF.

Comprovou-se a sintonia do Estatuto do IFF com os ideais de Freire, a partir das seguintes unidades de sentido: a justiça social, emancipação dos sujeitos, com o trabalho como princípio educativo, a pesquisa e extensão como instrumentos de diálogo com o território no qual vivem os alunos, participação da comunidade por meio de conselhos e comissões permanentes e paritárias, em que possibilitam um ambiente mais democrático. Destacam-se também as unidades de sentido relativas aos pactos com uma educação inclusiva e com o desenvolvimento socioeconômico e cultural, reforçando, portanto, a máxima da escola como um lócus de aprendizagens diárias e compartilhadas, afinal "ensinar não é transferir conhecimento, mas criar possibilidades para a sua produção ou a sua construção (FREIRE, 2017, pg.47).

Assim, a análise aponta que o IFF tem uma grande probabilidade de resguardar as ideias de Paulo Freire, porquanto suas perspectivas de uma educação para a democracia, comprometida com a inclusão social e com a formação de pessoas autônomas, ficam registradas na documentação analisada. Falamos em probabilidade, pois dependerá da concretização do trabalho coletivo e do comprometimento da comunidade escolar, questões que demandam pesquisas empíricas. Quanto mais, coletivamente, a escola se configurar, mais próxima estará da qualidade educacional, porque só a partir de procedimentos de escuta ativa e participação profunda nos rumos do trabalho pedagógico e institucional poderão gerar condições para uma efetiva gestão democrática da escola pública. 


\section{REFERÊNCIAS}

AFONSO, Almerindo Janela. Estado, políticas e gestão da educação: resistência ativa para uma agenda democrática com justiça social. Revista Brasileira de Política e Administração da Educação-Periódico científico editado pela ANPAE, v. 36, n. 2, p. 403-428, 2020. Disponível em: https://www.seer.ufrgs.br/ rbpae/article/view/103519. Acesso em 15. dez. 2020

ANTIQUEIRA, L.S; MACHADO, C. C. Análise textual discursiva na pesquisa sobre formação de professores de matemática. Revista Pesquisa Qualitativa, v. 8, n. 19, p. 863-888, 2020. Disponível em: https://editora.sepq.org.br/rpq/ article/view/360. Acesso em: 05. jan.2021.

ARROYO, Miguel Gonzalez. A Educação Profissional e Tecnológica nos interroga. Que interrogações?. Educação Profissional e Tecnológica em Revista-ISSN 2594-4827, v. 3, n. 1, 2019. Disponível em: https://ojs2.ifes.edu. br/index.php/ept/article/view/1321. Acesso em: 04.jan.2021

AU, W. Lutando com o texto: contextualizar e recontextualizar a pedagogia crítica de Freire. In: APPLE, Michael W; AU, Wayne; GANDIN, Luís A. Educação crítica: análise internacional. Porto Alegre: Artmed, 2011.

BRASIL. Decreto $\mathbf{n}^{\circ} \mathbf{2 . 2 0 8}$, de 17 de abril de 1997. Regulamenta o $\ 2^{\circ}$ do art. 36 e os arts. 39 a 42 da Lei n ${ }^{\circ}$ 9.394, de 20 de dezembro de 1996, que estabelece as diretrizes e bases da educação nacional. Brasília, DF, 1997.Disponível em: http:// www.planalto.gov.br/ccivil_03/decreto/d2208.htm. Acesso em: 06 de nov. de 2020.

BRASIL. Decreto $\mathbf{n}^{\circ}$ 5.154, de 23 de julho de 2004. Regulamenta o $\ 2^{\circ}$ do art. 36 e os arts. 39 a 41 da Lei no 9.394 , de 20 de dezembro de 1996, que estabelece as diretrizes e bases da educação nacional. Brasília, DF, 2004. Disponívelem: <http:/ / www.planalto.gov.br/ccivil_03/_ato2004-2006/2004/decreto/d5154.htm> Acesso em:06 de nov. de 2020. 
BRASIL. Ministério da Educação. Instituto Federal de Educação, Ciência e Tecnologia: um novo modelo em educação profissional e tecnológica:concepção e diretrizes. Brasília, DF: Ministério da Educação; Secretaria de Educação Profissional e Tecnológica, 2010. Disponível em: http://portal.mec.gov.br/index.php?option=com_ docman\&view $=$ download $\&$ alias $=6691$-if-concepcaoediretrizes\&category_ slug=setembro-2010-pdf\&Itemid=30192. Acesso em: 26.jan.2021

BRASIL. Plataforma Nilo Peçanha - Cursos, Matrículas, Ingressantes, Concluintes, Vagas e Inscritos por Tipo de Curso e Tipo de Oferta. Brasília, 2020. Disponível em:<http://plataformanilopecanha.mec.gov.br/2020.html> Acesso em: 05 de nov. de 2020

BEMVINDO, Vitor; MACIEL, Cosme L. Almeida (org.). Contraescola: apontamentos introdutórios. In: BEMVINDO, Vitor; MACIEL, Cosme L. Almeida. Contraescola: a experiência do instituto politécnico de Cabo Frio. Marília: Lutas Anticapital, 2020. p. 15-28.

COSTA, Alyne. Aqui quem fala é da terra. Pág. 135-157. IN: LATOUR, Bruno. Onde Aterrar? - Como se orientar politicamente no Antropoceno. Rio de Janeiro: Bazar do Tempo, 2020.

FERREIRA, S. M. L.; DA SILVA, R. M; DA NÓBREGA CARREIRO, G. A análise textual discursiva na pesquisa qualitativa no ensino de filosofia: peneiradas intempestivas no PROF-FILO. Revista Pesquisa Qualitativa, v. 8, n. 19, p. 800 834, 2020. Disponível em: https://editora.sepq.org.br/rpq/article/view/369. Acesso em: 05. jan.2021

FREIRE, Paulo. Política e Educação: ensaios. 5 ed. São Paulo: Cortez, 2001. . Conscientização: Teoria e prática da libertação: Uma introdução ao pensamento de Paulo Freire. $3^{\text {a }}$ ed. São Paulo: Centauro, 2006. . Educação e mudança. 30. ed. Rio de Janeiro: Paz e Terra, 2007. 
Sociedade fechada e inexperiência democrática. In. FREIRE, Paulo. Educação como prática da liberdade. Rio de Janeiro: Paz e Terra, 1967. (Cap. 2 - p. 65-84)

Pedagogia da autonomia: saberes necessários à prática educativa. 55. ed. Rio de Janeiro: Paz e Terra, 2017.

FRIGOTTO, Gaudêncio. Juventude com vida provisória e em suspenso. Rio de Janeiro, UERJ/FAPERJ e CNPq, Documentário, 2009. Disponível em 3 partes: https://www.youtube.com/watch?v=yXj6pTXn7zs; https://www. youtube.com/watch?v=eUCShbnNPRQ; https:/ /www.youtube.com/watch?v=Iz8m2mgNLY.Acesso em: 05. jan. 2020

GOLDENBERG, M. A arte de pesquisar - Como fazer pesquisa qualitativa em ciências sociais. $12^{\circ}$ ed. Rio de Janeiro/São Paulo: Record, 2011.

GRAMSCI, A. Os intelectuais e a organização da cultura. Rio de Janeiro: Civilização Brasileira, 1978.

GUIDOTTI, C.; HECKLER, V. O compreender com a ATD em uma etnopesquisa-formação com professores de ciências. Revista Pesquisa Qualitativa, v. 8, n. 19, p. 768-784, 2020. Disponível em: https://editora.sepq. org.br/rpq/article/view/365. Acesso em: 05. jan.2021

IFF. Resolução no 40: aprova a reformulação do Estatuto do Instituto Federal de Educação, Ciência e Tecnologia Fluminense. Campos dos Goytacazes, RJ, 2017. Disponível em: http://cdd.iff.edu.br/documentos/resolucoes/2017/ resolucao--40 . Acesso em: 26. jan.2021.

IFF. Projeto Político-Pedagógico Institucional (PPI-2018-2022). Campos dos Goytacazes, RJ, 2018. Disponível em: http://portal1.iff.edu.br/ensino/ arquivos/ppi-2018-2022.pdf/view. Acesso em: 12. jan. 2021

IFF. Edital No 140 - Reitoria - 23 de Dezembro de 2020: Processo de Seleção de Projetos de Cultural e Diversidade e seleção de estudantes bolsistas e voluntários. Campos dos Goytacazes, RJ, 23 dez. 2020. p. 1-7. Disponível em: http://portal1. iff.edu.br/reitoria/noticias/iff-divulga-edital-de-selecao-de-projetos-de-culturae-d. Acesso em: 12 jan. 2021 
LATOUR, Bruno. Onde Aterrar? - Como se orientar politicamente no Antropoceno. Rio de Janeiro: Bazar do Tempo, 2020.

LIBÂNEO, José Carlos. Organização e gestão da escola: teoria e prática. 5.ed. rev. ampl. Goiânia: Livros MF, 2008.

Democratização da Escola Pública: a pedagogia crítico-social dos conteúdos. 19. ed. São Paulo: Edições Loyola, 2003. (Coleção Educar).

LÜDKE,Menga; ANDRÉ, Marli. E.D A. Pesquisa em educação: abordagens qualitativas. $2^{\text {a }}$ Ed.Rio de Janeiro, Grupo GEN, E.P.U, 2020.

LÜCK, Heloisa et. al. A escola participativa: o trabalho do gestor escolar. 10 ed. Petrópolis, RJ: Vozes, 2011.

MESQUITA, N. A. da S. Perspectivas formativas de cursos de licenciatura em química: o desvelar dos projetos pedagógicos a partir da análise textual discursiva. Revista Pesquisa Qualitativa, v. 8, n. 19, p. 863-888, 2020. Disponível em: https://editora.sepq.org.br/rpq/article/view/360. Acesso em: 05. jan.2021

MOURA, D. H. Educação básica e educação profissional e tecnológica: dualidade histórica e perspectivas de integração. Holos, [s. 1.], v. 2, p. 4-30. 2007. Disponível em: http://www2.ifrn.edu.br/ojs/index.php/holos/article/view/11. Acesso em: 20. jan. 2021.

MORAES, R; DO CARMO GALIAZZI, M. Análise textual: discursiva. $3^{\mathrm{a}}$ Ed. Editora Unijuí, 2016.

MOREIRA, Antônio Flávio Barbosa; CANDAU, Vera Maria. Indagações sobre currículo: currículo, conhecimento e cultura. Brasília: Ministério da Educação, Secretaria de Educação Básica, 2007. Disponível em: http://portal.mec.gov.br/ seb/arquivos/pdf/Ensfund/indag3.pdf. Acesso em: 04 de nov. de 2020

MOTTA, Vânia Cardoso; FRIGOTTO, Gaudêncio. Por que a urgência da reforma do ensino médio? Medida Provisória no 746/2016 (Lei no 13.415/2017). Educação \& Sociedade, v. 38, n. 139, p. 355-372, 2017. Disponível em https:/ / www.scielo.br/pdf/es/v38n139/1678-4626-es-38-139-00355. Acesso em: 12 dez. 2020 
PACHECO, Eliezer Moreira. Os Institutos Federais: uma revolução na educação profissional e tecnológica. Brasília, 2010. Disponível em:http:// proedu.rnp.br/bitstream/handle/123456789/1274/Os\%20institutos\%20 federais\%20-\%20Ebook.pdf?sequence $=1$. Acesso em: 04 de nov. de 2020 .

RAMOS, Marise Nogueira. Concepção de Ensino Médio Integrado à Educação Profissional. Superintendência de Ensino Médio da Secretaria de Educação do Estado do Rio Grande do Norte, em Natal e Mossoró. Rio Grande do Norte, 2007. Disponível em: http:// forumeja.org.br/go/sites/forumeja.org. br.go/files/concepcao_do_ensino_medio_integrado5.pdf . Acesso em: 03 de nov. de 2020.

História e política da educação profissional. Curitiba: Instituto Federal do Paraná, 2014. (Coleção Formação Pedagógica; v. 5). Disponível em: https://curitiba. ifpr.edu.br/wp-content/uploads/2016/05/Hist\%c3\%b3ria-e-pol\%c3\%adticada-educa \%c3\%a7\%c3\%a3o-profissional.pdf Acesso em: 26. jan. 2021

SILVA, Tomaz Tadeu. Currículo e identidade social: territórios contestados. In: SILVA, T.T (Org.) Alienígenas na sala de aula: uma introdução aos estudos culturais em educação (p.190-207). Petrópolis, Vozes, 1995.

SOUZA, Ângelo Ricardo de. As condições de democratização da gestão da escola pública brasileira. Ensaio: avaliação e políticas públicas em Educação, v. 27, n. 103, p. 271-290, 2019.

TRIBUNAL DE CONTAS DA UNIÃO. Auditoria operacional Fiscalização de orientação centralizada. Rede Federal de Educação Profissional. Brasília, 2013. Disponível em: https://tcu.jusbrasil.com.br/jurisprudencia/315889946/2 606220119? ref=juris-tabs. Acesso em: 04 de nov. de 2020

TRIVIÑOS, Augusto Nibaldo Silva. Introdução à pesquisa em ciências sociais.: a pesquisa qualitativa em educação. São Paulo: Atlas, 2008. 


\section{Arthur da Rezende da Silva}

Doutorando em Educação pela Universidade Católica de Petrópolis, Estado do Rio de Janeiro (UCP - Petrópolis). Mestre em Planejamento Regional e Gestão de Cidades pela Universidade Cândido Mendes (UCAM) em Campos dos Goytacazes, RJ. Especialista em Literatura, Memória Cultural e Sociedade, pelo Instituto Federal Fluminense (IFF). Especialista em Psicopedagogia Clínica e Institucional pela Universidade São Camilo (Espírito Santo). Licenciado em Letras/Literatura (Universidade Iguaçu - Itaperuna-RJ). Concursado como Técnico em Assuntos Educacionais (TAE), cargo de nível superior da área pedagógica, do Instituto Federal Fluminense no Campus Santo Antônio de Pádua e Professor efetivo da Fundação de Apoio à Escola Técnica do Estado do Rio de Janeiro (FAETEC) - 20 horas, atuando na Licenciatura em Pedagogia da FAETEC de Santo Antônio de Pádua. Atualmente é Diretor-Geral do Instituto Federal Fluminense - Campus Santo Antônio de Pádua, RJ, tendo sido reeleito para o quadriênio de 2020 a 2024. E-mail: arezende@iff.edu.br

\section{Rafael Bastos Costa de Oliveira}

Pós-Doutorado em andamento, no Programa de Pós-Graduação em Ciência Política, da Universidade Federal do Rio Grande do Sul, sob supervisão do professor Dr. Rodrigo Stumpf González (2021). Doutor em Políticas Públicas e Formação Humana pela Universidade do Estado do Rio de Janeiro (2015) e mestre pelo mesmo programa (2010). É especialista em Metodologia do Ensino e da Pesquisa em Educação Física, Esporte e Lazer, pela Universidade Federal da Bahia (2008). Graduado em Licenciatura em Educação Física pela UFBA (2006). Possui Bacharelado em Ciências Sociais, pela Universidade Federal do Rio de Janeiro (2016). Professor Adjunto da Universidade do Estado do Rio de Janeiro (UERJ), desde 2016.2, alocado na Faculdade de Educação e na Faculdade de Formação de Professores. É docente do Programa de Pós-Graduação em Políticas Públicas e Formação Humana (PPFH). Atua como Pesquisador Associado do Laboratório de Políticas Públicas (LPP) e coordena o Projeto de Extensão do Grupo Estratégico de Análise Superior (GEA-ES / LPP). Coordena, desde 2018.2, a disciplina Políticas Públicas em Educação - Consórcio CEDERJUAB. É professor adjunto da Universidade Católica de Petrópolis, desde 2016.1, vinculado ao Programa de Pós-Graduação em Educação (PPGE) e ao curso de Licenciatura em Pedagogia. Coordena o Grupo de Pesquisa em Educação, Estado, Sociedade Civil e Participação Política (GPESP). Tem experiência profissional na Educação Básica (E. Infantil, E. Fundamental, E. Médio e EJA) assim como na Educação Superior (presencial e a distância), atuando em cursos de graduação e pós-graduação, especificamente na área de Educação, Políticas Educacionais, Políticas Públicas, Formação Humana, Sociologia da Educação, Ações Afirmativas, Formação de Gestores Públicos e Educação Física. Pesquisa a Participação Política na formulação de Políticas Educacionais no Brasil. E-mail: rafael.oliveira@ucp.br 